\title{
Teknologi Virtualisasi Openvz dan Kernel- Based Virtual Machine sebagai Layanan IaaS pada Jaringan Enterprise
}

\author{
Abdul Aziz, Adita Tarkono \\ Jurusan Teknik Informatika dan Komputer \\ Politeknik Negeri Jakarta \\ Depok- Indonesia \\ abdul.aziz@tik.pnj.ac.id, adita.tarkono@mhsw.pnj.ac.id
}

Diterima: 14 Maret 2016. Disetujui: 4 April 2016. Dipublikasikan: Mei 2016

\begin{abstract}
Abstrak - Server fisik saat ini memiliki perangkat keras yang sangat baik dalam menjalankan pekerjaan secara multitasking. Hal ini karena perangkat keras pada server fisik memiliki jumlah prosesor dan inti pemrosesan yang banyak serta didukung dengan kapasitas memori yang besar. Penggunaan server fisik secara tradisional sangat tidak efektif dalam memanfaatkan kemampuan multitasking dari server fisik. Selain itu juga, penggunaan satu sistem operasi pada server fisik untuk berbagai keperluan dapat menimbulkan konflik pada perangkat lunak. Teknologi virtualisasi mampu menjadi jawaban untuk mengatasi masalah-masalah tersebut karena mampu mengutilisasi secara penuh kemampuan server fisik dengan menciptakan mesin-mesin virtual yang berjalan bersamaan pada server fisik. Dengan adanya mesin-mesin virtual pada server fisik yang seolah-olah merupakan server fisik yang berjalan dengan sistem operasi masing-masing, mampu mengatasi masalah konflik pada perangkat lunak. OpenVZ dan Kernel-based Virtual Machine (KVM) merupakan teknologi virtualisasi bersifat bebas dan open source yang banyak digunakan. OpenVZ dan KVM memiliki kelebihan dan kekurangan masingmasing. Pada pengujian yang dilakukan, OpenVZ memiliki performa yang lebih baik dari KVM. Namun KVM memiliki kelebihan dari OpenVZ karena mampu mendukung banyak jenis sistem operasi yang bisa digunakan oleh mesin virtual yang dibuat.
\end{abstract}

Kata kunci: server; virtualisasi; mesin virtual; kernelbased virtual machine; openvz.

\section{Pendahuluan}

Perkembangan kemampuan perangkat keras saat ini sudah sangat baik. Umumnya prosesor kini memiliki lebih dari satu inti, sehingga dapat memproses banyak pekerjaan sekaligus dalam satu waktu. Namun dalam penerapannya, rupanya kemampuan dari perangkat keras tidak digunakan secara maksimal. Sumber daya dari perangkat keras tersebut tidak digunakan secara penuh bila suatu server fisik hanyak mengerjakan suatu pekerjaan yang spesifik. Teknologi virtualisasi hadir untuk memanfaatkan seluruh sumberdaya perangkat keras yang tersedia pada server fisik sehingga sumber daya tersebut dapat digunakan secara penuh.

Teknologi virtualisasi pada server memungkinkan suatu server fisik dapat digunakan untuk menjalankan beberapa sistem operasi dan services pada saat yang sama dengan menciptakan server - server secara virtual sehingga seolah - olah memiliki banyak server [1]. Akibatnya sumber daya pada server fisik tersebut dapat digunakan secara maksimal dan mampu melayani berbagai macam keperluan.

Teknologi virtualisasi ini merupakan salah satu dari layanan komputasi awan atau yang biasa disebut dengan cloud computing yang berupa infrastructure as a service (IaaS) [2][3]. IaaS ini sendiri merupakan layanan dasar dari cloud computing yang menyediakan layanan dalam bentuk infrastruktur berupa komputasi, kapasitas penyimpanan, dan jaringan yang disesuaikan dengan permintaan pengguna dimana untuk dapat memberikan layanan tersebut digunakanlah teknologi virtualisasi yang dapat mampu menyesuaikan sumber daya yang ada seperti kemampuan komputasi, memori, besaran media penyimpanan, serta jaringan komunikasi sesuai dengan permintaan pengguna [4][3][5]. Terdapat dua teknologi virtualisasi yang sering digunakan, yaitu Container Virtualization yang menggunakan OpenVZ dan Full Virtualization yang menggunakan Kernel-Based Virtual Machine atau KVM. Masing-masing teknologi ini memiliki kekurangan dan kelebihan [6].

Observasi yang telah dilakukan dalam kegiatan perencanaan pengembangan infrastruktur jaringan enterprise ternyata dibutuhkan layanan lainnya yang perlu ditambahkan. Layanan-layanan tersebut membutuhkan sumberdaya komputasi 
berupa server agar layanan tersebut dapat beroperasi. Namun, ketersediaan server fisik yang ada tidak dapat memenuhi kebutuhan untuk dapat menampung beberapa layanan baru yang rupanya memiliki persyaratan sistem operasi dan aplikasi pendukung yang berbeda-beda. Teknik virtualisasi server yang akan diimplementasikan dalam bentuk layanan IaaS dipilih untuk dapat menyelesaikan masalah tersebut. Dengan ketersediaan jumlah server fisik yang ada mampu menampung berbagai layanan yang dibutuhkan tanpa timbulnya konflik pada sistem operasi dan aplikasi pendukung yang dibutuhkan oleh layanan-layanan tersebut. Penelitian ini bertujuan untuk membahas tentang layanan komputasi awan, langkah implementasi teknologi virtualisasi layanan komputasi awan IaaS, pemilihan teknologi virtualisasi yang akan digunakan sesuai kebutuhan, implementasi teknologi virtualisasi OpenVZ dan KVM, dan pemanfaatan kelebihan penggunaan komputasi awan Iaas dan teknologi virtualisasi.

Komputasi awan atau dikenal dengan sebutan cloud computing merupakan gabungan pemanfaatan teknologi komputer (komputasi) dalam suatu jaringan dengan pengembangan berbasis jaringan atau internet (awan) yang mempunyai fungsi untuk menjalankan program atau aplikasi melalui komputer-komputer yang terkoneksi pada waktu yang sama [2][3].

Terdapat tiga jenis layanan yang diberikan oleh komputasi awan, yaitu[4][3]:

1. Software as a Service (SaaS)

Merupakan layanan komputasi awan dimana pengguna dapat menggunakan perangkat lunak yang telah disediakan oleh penyedia komputasí awan. Pengguna cukup tahu bahwa perangkat lunak bisa berjalan dan bisa digunakan dengan baik. Contoh dari layanan SaaS ini antara lain seperti Google Docs, Gmail, GTalk, Dropbox. Keuntungan dari penggunaan SaaS ini adalah kita tidak perlu membeli lisensi perangkat lunak lagi karena pengguna cukup berlangganan kepada penyedia SaaS berdasarkan pemakaian.

2. Platform as a Service (PaaS)

Merupakan layanan komputasi awan dimana pengguna mendapatkan platform untuk menjalankan aplikasi yang telah dibuat. Pengguna tidak perlu menyiapkan host dan merawat host tersebut, yang perlu dilakukan pengguna hanyalah memastikan bahwa aplikasi miliknya berjalan dengan baik. Contoh layanan PaaS yaitu seperti web hosting, Amazon Web Service, Windows Azure. Keuntungan dari penggunaan layanan $\mathrm{PaaS}$ adalah pengguna dapat fokus terhadap aplikasi miliknya dikarenakan untuk masalah host sudah ditangani oleh penyedia PaaS.
3. Infrastructure as a Service (IaaS)

Merupakan layanan dari komputasi awan dimana pengguna dapat menyewa infrastruktur IT seperti unit komputasi, penyimpanan data, memori, jaringan komputer dan konfigurasi lainnya. Pada layanan IaaS pengguna seperti menyewa komputer yang masih kosong. Pengguna diharuskan mampu dalam mengkonfigurasi sendiri layanan ini sesuai dengan kebutuhannya. Contoh layanan IaaS yaitu seperti penyedia layanan VPS, Digital Ocean, Amazon EC2, Rackspace Cloud.

Virtualisasi merupakan suatu teknik menciptakan sesuatu dalam bentuk maya atau simulasi dari sesuatu yang memiliki fisik yang nyata [7]. Dengan menerapkan teknik virtualisasi pada server, akan diperoleh banyak server-=server baru dalam bentuk maya pada satu server fisik. Server-server tersebut dapat bekerja seperti server fisik dan secara logika akan tampak seperti serverserver fisik baru yang memiliki perangkat keras, sistem operasi dan perangkat lunaknya masingmasing [8][9].

Teknik virtualisasi server yang dapat menciptakan server-server virtual dalam suatu server fisik dapat digunakan untuk menangani masalah tersebut. Dengan virtualisasi server, server-server virtual tersebut dapat memiliki sistem operasinya masing-masing sehingga masalah konflik pada sistem operasi dan perangkat lunak dapat diatasi. Selain itu dengan teknik ini, kemampuan dari server fisik dapat terutilisasi secara maksimal dengan begitu biaya juga dapat ditekan karena tidak diperlukannya lagi pembelian server fisik yang baru untuk mengatasi konflik pada sistem operasi dan perangkat lunak [9][10].

Server fisik atau physical server merupakan perangkat komputer dalam bentuk fisik dengan perangkat keras yang dirancang khusus untuk kebutuhan server dengan memiliki sumber daya komputasi yang besar dan mampu menyala dalam waktu yang sangat lama. Saat ini server fisik kebanyakan hadir dengan prosesor yang memiliki banyak inti, dan tidak hanya itu banyak juga server fisik yang dapat menampung lebih dari satu prosesor, dengan begitu server fisik saat ini sangat mumpuni dalam melakukan banyak kegiatan sekaligus dalam satu waktu (multitasking) [11].

Hypervisor merupakan sebuah sistem dimana server virtual yang dibuat dapat berjalan. Hypervisor ini dipasang pada host (server fisik) yang akan dijadikan sebagai server virtualisasi. Hypervisor berfungsi untuk mengatur sumber daya yang ada dan membaginya kepada server virtual yang telah dibuat [7]. Dengan adanya hypervisor, sebuah server fisik dapat membuat banyak server virtual yang mampu menjalankan berbagai macam sistem operasi sehingga seolah-olah memiliki banyak server fisik. 
Proxmox Virtual Environment (VE) adalah salah satu distro Linux berbasis Debian 64 bit yang mempunyai fungsi khusus sebagai hypervisor virtualisasi. Proxmox berjalan dengan mode text dan dapat dikonfigurasi secara remote melalui web based sehingga memudahkan penggunaannya. Proxmox VE mendukung beberapa jenis teknologi virtualisasi seperti Kernel-based Virtual Machine dan OpenVZ. Proxmox VE menggunakan kernel linux khusus untuk virtualisasi menjadikan Proxmox VE sebuah Bare Metal Virtualization Platform yang handal [6][12]. Pemilihan Proxmox VE hypervisor karena didalamnya sudah terdapat teknologi virtualisasi yang menggunakan Kernelbased Virtual Machine dan OpenVZ selain itu juga Proxmox VE memiliki lisensi yang bersifat gratis dan open source [13].

Kernel-based Virtual Machine (KVM) adalah salah satu teknologi virtualisasi yang dikembangkan oleh Linux. KVM merupakan sebuah solusi untuk melakukan virtualisasi pada Linux dengan perangkat keras type x86 (64-bit). KVM diimplementasikan sebagai modul kernel loadable sehingga mampu menjalankan berbagai macam sistem operasi tanpa modifikasi. Ada dua prinsip desain utama yang diadopsi oleh KVM dengan tujuan agar KVM menjadi teknologi virtualisasi dengan kinerja tinggi dan melampaui open source untuk virtualisasi lainnya [11].

Pertama, karena KVM didesain setelah kemunculan teknologi virtualisasi dibantu perangkat keras (hardware assisted virtualization), KVM perlu mengimplementasikan fitur yang telah disediakan oleh perangkat keras. KVM membutuhkan prosesor Intel VT-X atau AMD-V dan menggunakan fitur tersebut untuk virtualisasi CPU. Karena memanfaatkan dukungan perangkat keras yang telah tersedia, KVM mampu merancang solusi hypervisor yang optimal tanpa memerlukan beban yang mendukung perangkat keras dan tidak perlu memodifikasi sistem operasi pada mesin virtual.

Kedua, tim KVM menerapkan pepatah "don't reinvent the wheel". Terdapat banyak komponen yang dibutuhkan agar KVM mampu memvirtualisasi CPU dan memori, seperti: pengatur memori, penjadwal proses, I/O stack, device drivers, pengatur keamanan, network stack, dan sebagainya. Faktanya, suatu hypervisor adalah sistem operasi khusus, hanya saja tujuan hypervisor berbeda dengan tujuan umum sistem operasi lainnya. Hypervisor menjalankan mesin virtual, bukan aplikasi-aplikasi. Karena kernel Linux sudah mencakup fitur inti yang diperlukan oleh hypervisor dan Linux telah menjadi platform skala enterprise yang stabil selama lebih dari lima belas tahun, KVM dibangun berdasarkan kernel Linux agar lebih efisien, daripada menulis semua komponen yang dibutuhkan seperti pengatur memori dan penjadwal dari awal [14][8].

OpenVZ merupakan teknologi virtualisasi pada tingkat sistem operasi yang berbasis pada kernel Linux yang telah dimodifikasi sehingga memungkinkan sebuah server fisik untuk menjalankan beberapa mesin virtual yang disebut containers. Container sering dianalogikan dengan chroot atau jail, tetapi container jauh lebih baik dalam hal isolasi, kemananan, fungsionalitas, dan manajemen resources. OpenVZ terdiri dari sebuah kernel Linux khusus dan beberapa user-level tool. OpenVZ sangat portable, tidak mengandalkan dukungan VT pada CPU, sehingga tersedia untuk sejumlah tipe CPU termasuk x86, x86-64, IA-64, PowerPC dan SPARC [8].

OpenVZ hanya dapat melakukan virtualisasi untuk sistem operasi berbasis kernel Linux. OpenVZ dapat mencapai performa, skalabilitas, dan densitas yang lebih baik karena terdapat satu kernel Linux yang berjalan pada host fisik dimana setiap container hanya mengambil sumber daya komputasi yang diperlukan untuk menjalankan proses didalamnya saja, tidak perlu untuk keseluruhan sistem operasi [8]. Sebuah basic-container dapat menambahkan 8 sampai 14 proses pada host. OpenVZ juga dapat menangani aplikasi tingkat lanjut seperti aplikasi multi-threaded Java.

Keuntungan lain dari OpenVZ adalah menawarkan berbagai parameter manajemen sumber daya komputasi yang dinamis antara lain, penggunaan memori, jumlah proses, tingkat penggunaan CPU, penggunaan media penyimpanan, yang semuanya itu dapat diubahubah saat container sedang berjalan. OpenVZ juga mendukung kuota penggunaan besaran media penyimpanan di dalam container [14][8].

Mesin virtual (Virtual Machine) atau yang biasa disebut dengan server virtual adalah server atau komputer yang tidak memiliki perangkat keras secara fisik, namun dapat bekerja seperti server atau komputer fisik [15][13]. Mesin virtual ini merupakan hasil dari penerapan virtualisasi server. Mesin virtual ini memiliki sistem operasinya sendiri, dan masing-masing mesin virtual dapat memiliki sistem operasi yang berbeda-beda, dengan begitu satu server fisik mampu menjalankan berbagai macam sistem operasi dan perangkat lunak untuk berbagai kebutuhan. Mesin virtual ini memiliki sifat yang lebih fleksibel dalam pengaturan perangkat keras daripada mesin secara fisik. Pada mesin virtual, proses penyesuaian kebutuhan hardware dapat dilakukan dengan mudah melalui hypervisor [15].

Mesin-mesin virtual, walau berada pada satu host yang sama, tetapi antar satu mesin dengan mesin yang lainnya saling terisolasi. Hal itu karena hypervisor benar-benar melakukan pemisahan pada 
mesin-mesin virtual menjadi blok-blok mesin virtual sehingga secara logika suatu mesin virtual dapat terlihat sebagai satu mesin fisik secara utuh sehingga keamanannya tergantung dari masingmasing sistem operasi dan perangkat lunak yang dipasang [12][15].

Sistem operasi adalah seperangkat program yang mengelola sumber daya perangkat komputer dan menyediakan layanan umum untuk aplikasi perangkat lunak. Sistem operasi merupakan jenis yang paling penting dari perangkat lunak sistem dalam sistem komputer. Tanpa sistem operasi, sistem komputer tidak lebih sekedar dari sekumpulan komponen elektronik dan komponen mekanik [1][5]. Sistem operasi bertindak seperti penterjemah antara pengguna aplikasi dengan perangkat keras. Seorang pengguna berinteraksi dengan sistem komputer melalui sebuah aplikasi, seperti aplikasi pengolah kata, permainan, atau program aplikasi lain yang dirancang untuk tujuan tertentu. Dalam menggunakan aplikasi tersebut, aplikasi tidak akan peduli bagaimana caranya pengguna memasukkan informasi ke dalam aplikasi, seperti melalui keyboard. Sistem operasi yang bertanggungjawab terhadap komunikasi antara aplikasi dengan perangkat keras. Dalam contoh lain, ketika pengguna menggunakan sebuah aplikasi, memasukan informasi melalui keyboard, ditampilkan dimonitor, disimpan pada media penyimpanan, atau kemudian dicetak di printer, semuanya diatur oleh sistem operasi.

Sistem operasi inilah yang bertugas menangani seluruh perangkat input dan output komputer. Dengan demikian sistem operasi memiliki kendali penuh terhadap sumber daya perangkat keras komputer dan mempunyai penjadwalan yang sistematis mencakup perhitungan penggunaan memori, pemrosesan data, penyimpanan data, dan sumber daya lainnya. Sistem operasi memiliki empat fungsi pokok, yaitu: mengontrol akses perangkat keras, manajemen file dan folder, menyediakan user interface, dan manajemen aplikasi.

Sysbench merupakan perangkat lunak aplikasi dengan tampilan antarmuka berupa text yang berjalan pada sistem operasi berbasis kernel linux. Sysbench dapat melakukan pengukuran performa perangkat keras seperti CPU, memori RAM, dan Harddisk. Sysbench memiliki lisensi penggunaan yang bebas, berbasis open source [15].

\section{Metode Penelitian TeKnologi VIRTUALISASI}

Server fisik merupakan komponen terpenting dalam pengimplementasian teknologi virtualisasi. Selain server fisik, dalam layanan komputasi awan, ketersediaan jaringan komputer juga merupakan suatu hal yang penting karena nantinya segala aktifitas komputasi akan dilakukan secara remote melalui jaringan komputer. Penelitian ini hanya menitikberatkan pada server fisik sesuai dengan ruang lingkup pekerjaan penulis. Server fisik yang digunakan meliputi dua komponen yaitu perangkat keras dan perangkat lunak.

\section{A. Komponen Perangkat Keras dan Lunak}

Server fisik yang akan digunakan harus memiliki komponen perangkat keras yang mampu melakukan multitasking yang baik seperti penggunaan prosesor yang memiliki banyak inti pemrosesan dan kapasitas memori yang besar. Hal ini dikarenakan server fisik yang digunakan harus mampu menjalankan banyak mesin-mesin virtual. Selain jumlah inti pemrosesan pada prosesor dan besaran memori, kapasitas media penyimpanan yang besar. Prosesor buatan Intel jenis Xeon dipilih karena prosesor tersebut memiliki inti pemrosesan yang banyak, selain itu prosesor Intel Xeon didesain khusus untuk keperluan server dan digunakan oleh banyak perusahaan pembuat server sehingga kemampuannya sebagai prosesor untuk sudah teruji baik pada penggunaannya. Selain itu server yang akan digunakan akan dipasang memory RAM sebesar 16 GB dan media penyimpanan berupa harddisk sebesar 2 TB.

Penggunaan komponen perangkat lunak, akan digunakan sistem operasi yang khusus untuk keperluan virtualisasi yang disebut dengan hypervisor. Proxmox Virtual Environment merupakan hypervisor yang akan digunakan karena hypervisor ini bersifat open source dan memiliki teknologi virtualisasi yang lengkap mencakup teknologi virtualisasi OpenVZ dan kernel-based virtual machine yang akan dianalisa. OpenVZ dan KVM dipilih untuk diimplementasikan karena kedua teknologi tersebut biasa dan banyak digunakan untuk membuat mesin virtual. Selain itu, teknologi tersebut memiliki lisensi penggunaan secara bebas dan bersifat open source yang berjalan pada dasar kernel berbasis Linux.

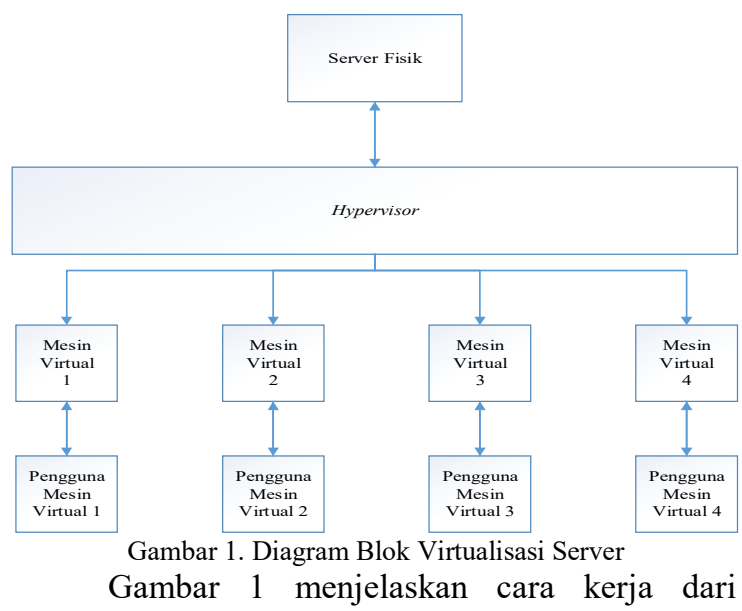
virtualisasi server dimana sumber daya komputasi 
yang dimiliki oleh server fisik akan diatur dan dikelola oleh sistem operasi khusus berupa hypervisor yaitu Proxmox Virtual Environment yang mana hypervisor tersebut telah mendukung teknologi virtualisasi OpenVZ dan KVM. Hypervisor akan mengatur dan mengelola serta membagi-bagi sumber daya komputasi yang dimiliki kepada mesin-mesin virtual yang dibuat. Mesin virtual yang dibuat akan berjalan diatas hypervisor sehingga akses mesin-mesin virtual kepada perangkat keras yang dimiliki server fisik akan dijembatani oleh hypervisor. Mesin-mesin virtual yang berjalan selanjutnya akan dikelola dan difungsikan untuk berbagai macam keperluan oleh pengguna mesin virtual. Pengguna mesin virtual dapat mengakses mesin-mesin virtual yang ada melalui jaringan komputer secara remote. Spesifikasi alat berupa server fisik yang akan digunakan dapat dilihat dalam Tabel 1.

TABEL 1. SPESIFIKASI SERVER FISIK

\begin{tabular}{|c|c|c|}
\hline No. & Komponen & Spesifikasi \\
\hline 1 & Prosesor & $\begin{array}{l}\text { Intel Xeon E3 } 1220 \text { V3 Quad } \\
\text { Core 3.1Ghz }\end{array}$ \\
\hline 2 & Papan Utama & Intel Serverboard S1200V3RP \\
\hline 3 & Memori RAM & $\begin{array}{l}\text { DDR } 3 \text { ECC UDIMM 4X4GB } \\
\text { Total } 16 \text { GB }\end{array}$ \\
\hline 4 & $\begin{array}{l}\text { Antarmuka } \\
\text { Jaringan }\end{array}$ & $\begin{array}{l}\text { Dual slot Intel Gigabit Network } \\
\text { Interface Card }\end{array}$ \\
\hline 5 & $\begin{array}{l}\text { Media } \\
\text { Penyimpanan }\end{array}$ & $\begin{array}{l}2 \text { X } 1 \text { TB HDD Sata } 7200 \text { RPM } \\
\text { Western Digital, Total } 2 \text { TB }\end{array}$ \\
\hline 6 & Server Case & Model Tower merk Dazumba \\
\hline 7 & PSU & Dazumba 450 Watt \\
\hline 8 & $\begin{array}{l}\text { Mouse dan } \\
\text { keyboard }\end{array}$ & $\begin{array}{l}\text { Standard USB Mouse and } \\
\text { keyboard }\end{array}$ \\
\hline 9 & Monitor & LED 16" merk AOC \\
\hline 10 & Sistem Operasi & Proxmox Virtual Environment? \\
\hline
\end{tabular}

III. Pengujian Dan Analisis Data

Pada penelitian ini dibahas penggunaan teknologi Kernel-based Virtual Machine dan OpenVZ untuk membangun suatu layanan komputasi awan berupa IaaS. Pengujian dilakukan terhadap teknologi virtualisasi yang digunakan untuk mengetahui manakah dari kedua teknologi tersebut yang memiliki performa lebih baik dalam melakukan komputasi. Terdapat tiga jenis pengujian yang akan dilakukan yaitu, pengujian performa komputasi CPU, pengujian performa Input/Output transfer file pada harddisk, dan pengujian performa memori RAM.

A. Prosedur dan pelaksanaan pengujian

Pengujian dilakukan dengan membuat dua buah mesin virtual menggunakan teknologi virtualisasi yang berbeda, namun diberikan kapasitas kemampuan komputasi yang sama dan sistem operasi yang sama. Spesifikasi mesin virtual dapat dilihat lebih detail pada Tabel 2.
TABEL 2. SPESIFIKASI MESIN VIRTUAL

\begin{tabular}{lcc}
\hline \multirow{2}{*}{ Komponen } & \multicolumn{2}{c}{ Besaran Nilai } \\
\cline { 2 - 3 } & KVM & OpenVZ \\
\hline CPU & $1 \mathrm{Core}$ & $1 \mathrm{Core}$ \\
Memori RAM & $512 \mathrm{MB}$ & $512 \mathrm{MB}$ \\
Kapasitas & $30 \mathrm{~GB}$ & $30 \mathrm{~GB}$ \\
Penyimpanan & & \\
Sistem Operasi & Centos $6.6-64 \mathrm{bit}$ & Centos $6.6-64 \mathrm{bit}$ \\
\hline
\end{tabular}

1. Pengujian CPU

Pada pengujian performa CPU yang dilakukan sebanyak empat kali dengan variabel berupa besaran nilai bilangan prima yang diproses didapatkan data seperti pada Tabel 3. Dalam bentuk grafis dapat dilihat pada Gambar 2.

TABEL 3. DATA PENGUJAN PERFORMA CPU

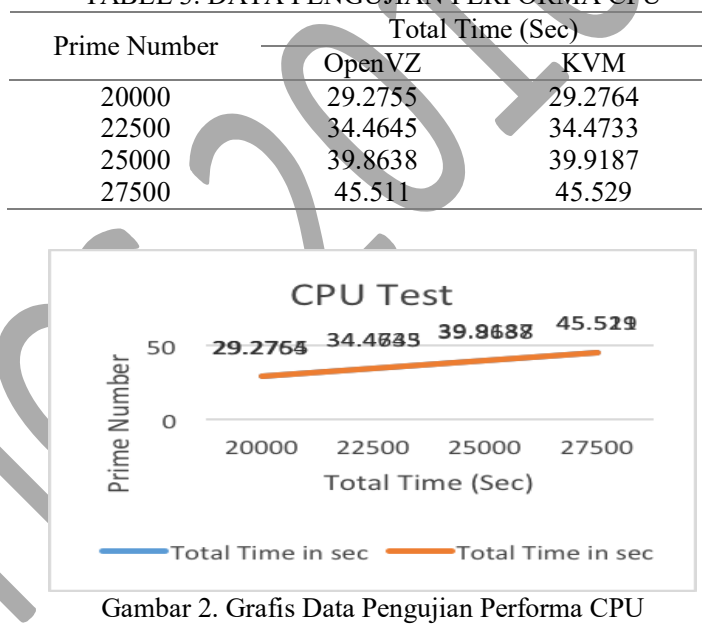

Untuk pengujian performa CPU, waktu yang paling kecil merupakan hasil yang terbaik.

2. Pengujian Performa Harddisk

Pada pengujian performa input / output transfer file pada harddisk yang dilakukan sebanyak empat kali dengan variabel berupa besaran nilai waktu maksimal pemrosesan didapatkan data seperti pada Tabel 4. Dalam bentuk grafis dapat dilihat pada Gambar 3.

\begin{tabular}{ccc}
\multicolumn{2}{c}{ TABEL 4. DATA PENGUJIAN PERFORMA HARDDISK } \\
\hline Max Time & \multicolumn{2}{c}{ Transfer Speed $(\mathrm{Mb} / \mathrm{sec})$} \\
\cline { 2 - 3 }$(\mathrm{Sec})$ & OpenVZ & KVM \\
\hline 100 & 2.3071 & 0.6079 \\
150 & 3.0323 & 0.9493 \\
200 & 3.4213 & 1.1719 \\
250 & 3.6812 & 1.3812 \\
\hline
\end{tabular}

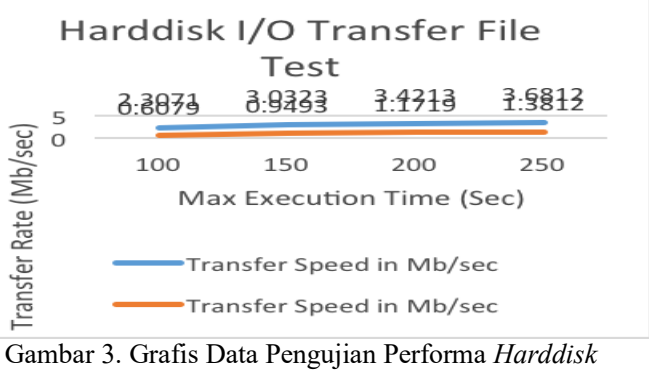


Untuk pengujian performa input/output transfer file pada harddisk, kecepatan transfer yang paling besar merupakan hasil yang terbaik.

3. Pengujian Performa Memori RAM

Pada pengujian performa memori RAM yang dilakukan sebanyak empat kali dengan variabel berupa besaran nilai blok dari data yang akan digunakan untuk menguji proses transfer data didapatkan data seperti Tabel 5. Dalam bentuk grafis dapat dilihat Gambar 4.

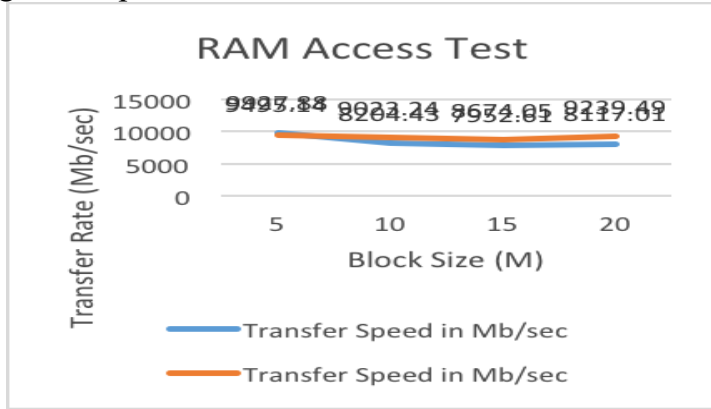

Gambar 4. Grafis Data Pengujian Performa Memori RAM

TABEL 5. DATA PENGUJIAN PERFORMA MEMORY RAM

\begin{tabular}{ccc}
\hline Block & \multicolumn{2}{c}{ Transfer Speed $(\mathrm{Mb} / \mathrm{sec})$} \\
\cline { 2 - 3 } Size $(\mathrm{M})$ & OpenVZ & KVM \\
\hline 5 & 9927.88 & 9495.14 \\
10 & 8204.43 & 9023.24 \\
15 & 7952.61 & 8674.05 \\
20 & 8117.01 & 9239.49 \\
\hline
\end{tabular}

Untuk pengujian performa memori RAM, kecepatan transfer yang paling besar merupakan hasil yang terbaik.

\section{B. Evaluasi pengujian}

Hasil dari data yang diperoleh dapat terlihat bahwa perbedaan teknologi virtualisasi memiliki perbedaan performa pada mesin virtual. Ini terjadi karena perbedaan teknik yang digunakan pada masing-masing teknologi virtualisasi tersebut.

Data hasil pada pengujian performa CPU, dapat terlihat bahwa perbedaan performa pada CPU tidak terlalu signifikan. Hal ini dapat tergambarkan pada Gambar 2 dimana grafis performa CPU pada OpenVZ dengan KVM hampir saling berhimpitan. Bila diperhatikan secara seksama data-data yang ada pada Tabel 3, walau perbedaanya sedikit, tetapi terlihat bahwa performa CPU dari OpenVZ sedikit lebih baik. Hal ini ditunjukkan oleh lebih kecilnya nilai total waktu pada OpenVZ dari pada KVM.

Pada pengujian performa input/output transfer file pada harddisk, terlihat sangat jelas adanya perbedaan performa. Hal ini dapat dilihat pada Gambar 3 dimana grafis performa transfer file pada OpenVZ lebih besar nilainya dari pada KVM. Bila diperhatikan secara seksama nilai-nilai pada Tabel 4 terlihat bahwa OpenVZ memiliki performa I/O lebih baik dari pada KVM.
Terakhir, dari data pada pengujian performa memori RAM, terlihat adanya perbedaan antara OpenVZ dengan KVM yang dapat dilihat pada Gambar 4. Keunggulan OpenVZ hanya terjadi pada saat pengujian menggunakan besaran nilai blok file yang kecil, sedangkan pada besaran nilai blok file yang besar, KVM unggul dari OpenVZ.

\section{KESIMPULAN}

Dari hasil pembuatan dan pengujian tugas akhir pada tulisan ini yaitu implementasi dan analisa teknologi virtualisasi OpenVZ dan Kernelbased Virtual Machine sebagai layanan komputasi awan berupa Infrastructure as a Service (IaaS) pada infrastruktur jaringan enterprise Jurusan Teknik Informatika dan Komputer Politeknik Negeri Jakarta dapat diambil kesimpulan sebagai berikut.

a. Teknologi virtualisasi mampu memanfaatkan kemampuan multitasking dari server fisik. Hal ini dibuktikan dari kemampuan server fisik menjalankan banyak mesin-mesin virtual pada satu waktu sekaligus.

b. Teknologi virtualisasi dapat menghemat biaya infrastruktur IT karena mampu mengurangi kebutuhan penambahan server fisik baru. Hal tersebut karena kebutuhan tersebut dapat dipenuhi dengan penggunaan mesin virtual sebagai pengganti server fisik.

c. Proxmox VE merupakan hypervisor dengan lisensi tidak berbayar yang menyediakan kebutuhan virtualisasi yang lengkap dengan adanya teknologi virtualisasi Kernel-based Virtual Machine dan OpenVZ didalamnya.

d. Dari hasil pengujian, teknologi virtualisasi OpenVZ memiliki performa komputasi yang lebih baik dari pada KVM.

e. Disisi kompatibilitas akan penggunaan sistem operasi pada mesin virtual, KVM lebih unggul dari OpenVZ karena mampu menjalankan lebih banyak jenis sistem operasi, tidak terbatas pada sistem operasi berbasis kernel Linux.

f. OpenVZ sangat baik digunakan bila mesin virtual hanya akan menggunakan sistem operasi berbasis kernel Linux serta ketika pengguna meminta kemudahan dari penginstalasian sistem operasi. OpenVZ tidak melakukan penginstalan sistem operasi dari awal, tetapi menggunakan template sistem operasi yang sudah dimodifikasi agar mampu berjalan pada kernel OpenVZ.

g. KVM sangat baik digunakan bila pengguna membutuhkan virtualisasi berupa desktop dan membutuhkan sistem operasi yang tidak berbasiskan kernel Linux. KVM dapat menjalankan berbagai macam sistem operasi karena tidak memerlukan sistem operasi yang dimodifikasi untuk dapat berjalan pada KVM. 


\section{REFERENSI}

[1] Rajo Kaciak, Gufron. Perbaikan Perangkat Komputer. Padang:Bung Hatta University Press, 2014.

[2] Wardani, Kusuma. Penerapan Cloud Computing di Instansi Pemerintah, 2013. http://ilmukomputer.org/2013/04/24/penerapan-cloudcomputing-di-instansi-pemerintah/ [diakses, 25 April 2015]

[3] Barrie Sosinsky, Cloud Computing Bible, Wiley Publishing, Inc., Indianapolis, ISBN: 978-0-470-90356, 2011.

[4] W. Purbo, Onno, Petunjuk Praktis Cloud Computing

[5] Indra Bayu, Teguh. Ratna Widiasari, Indrastanti. dan W. Chandra, Dian, Penerapan Teknologi Virtualisasi Tingkat Sistem Operasi pada Server Linux Ubuntu 8.04 menggunakan OpenVZ, Salatiga: Universitas Kristen Satya Wacana, 2010.

[6] Budiyanto, Alex, Pengantar Cloud Computing.

[7] Musajid, Akrom, Proxmox Cloud Computing. https://kelaskita.com/media/static/5352d9bcd446dc1686f5 fa49/proxmox-cloud-computing-virtualisasi.pdf, 2012 [diakses 25 April 2015].

[8] IDreg, Info Pengertian KVM, Xen, dan OpenVZ. http://www.idreg.net/, pengertian-kvm-xen-openvz/,2013. [diakses 9 Mei 2015].
[9] Ahmed, Monjur, Physical Server and Virtual Server: The Performance Trade-Offs. Bangladesh:Daffodil Institute of Information Technologi, 2013

[10] Ardianto, Novan. Widyawan. dan Sumaryono, Sujoko, Pengembangan Virtual Appliance Server dengan Metode Virtualisasi. Yogyakarta: Universitas Gajah Mada, 2012.

[11] Eka P, Ricky. Rachman, Andy. dan Wahyu H, Tri, Virtual Private Server (VPS) sebagai Alternatif Pengganti Dedicated Server. Surabaya: Institut Teknologi Sepuluh Nopember, 2010.

[12] Goldberg, Robert P, Architectural Principles for Virtual Computer System, Cambridge: Havard University, 2010.

[13] Suryono, Tito. dan Faruq Afif, Mohammad, Pembuatan Prototype Virtual Server Menggunakan Proxmox VE untuk Optimalisasi Resource Hardware di NOC FKIP UNS. Solo:IJNS, 2012.

[14] Adhiwibowo, Whisnumurti, Kernel-based Virtual Machine untuk Virtualisasi Database sebagai Solusi Kebutuhan Perangkat Keras Studi Kasus Implementasi Sistem Informasi Klinik Kecantikan. Semarang, Universitas Semarang, 2013.

[15] VMware, Virtualization Basic. http:/Www.vmware.com /virtualization/Virtualization-basics/, 2014 [diakses 1 April 2015]. 